\title{
Sintesis Membran Silika Kitosan Dari Abu Ampas Tebu (Bagasse)
}

\author{
Sjamsiah, Kurnia Ramadani, Hermawan \\ Jurusan Kimia, Fakultas Sains dan Teknologi, UIN Alauddin Makassar \\ Email: sjamsiahuca@yahoo.com
}

\begin{abstract}
Membrane is a polymer layer that can be used in the process adsorbsi metal ions. Membrane can be synthesized from silica dust bagasse that termodifikasi kitosan. The purpose of this research is to know the impact of the addition of a variety of silicate on the characteristics of the membrane silika-kitosan the bagasse to the adsorpsi metal ions $P b$. The content of silica in the bagasse to 73, $80 \%$. Membrane kitosan-silika be made with different variations of the composition of which is $1: 1 ; 1: 1,5 ; 1: 2 ; 1: 2,5$ and $1: 3$ and the ability of the adsorpsi the metal $\mathrm{Pb}$ in a row of $41 \%, 43,76 \%, 54,88 \%, 38,36 \%$ and 39, $6 \%$.. The application of membrane to the process adsorpsi metal ions $P b$ by membrane said with a ratio of $1: 2$ to concentrate $P b$ the beginning of the 50 parts per million. The use of membrane to the process readsorpsi to do with how to choose a membrane that has the adsorpsi of the membrane with a ratio of 1:2 be able to absorb metal Pb of 1 ppm. Membrane that has been used can be used with traffic readsorpsi, $2 \%$ in the membrane of every $1: 2$.
\end{abstract}

Keywords: kitosan, membrane, metal lead, silica dust bagasse

\section{PENDAHULUAN}

Tanaman tebu (saccharum officinarum) sebagai sumber terbesar gula terus meningkat seiring dengan meningkatnya jumlah penduduk, pendapatan, gaya hidup dan industri pangan. Selain itu, ampas tebu sebagai hasil samping dari pengelolahan tebu menjadi gula juga meningkat. Ampas tebu di industri gula masih belum termanfaatkan secara optimal, masih banyak ampas tebu yang melimpah setiap kali produksi. Hal ini memungkinkan limbah ampas tebu untuk dimanfaatkan lebih luas.

Ampas tebu biasa digunakan sebagai bahan baku pada pembuatan kertas. Akan tetapi masih banyak juga yang melakukan pembakaran secara langsung sehingga menimbulkan polusi bagi udara. Padahal menurut hasil penelitian Kristianingrum dkk. (2011) ampas tebu mengandung silika sekitar 55,5\% - 70\%. Kandungan silika tersebut dapat dimanfaatkan sebagai bahan baku untuk menghasilkan silika. Silika yang dihasilkan juga dapat diproses lebih lanjut untuk menghasilkan produk seperti membran silika. Membran silika merupakan suatu selaput yang dapat dijadikan sebagai suatu adsorben yang dapat mengadsorpsi logam berat yang dapat mencemari lingkungan

Membran Silika ampas tebu dapat digunakan dalam jangka waktu yang lama karena memiliki beberapa kelebihan yaitu stabil terhadap pengaruh mekanik, panas, pelarut organik dan kondisi $\mathrm{pH}$ ekstrim. Walaupun mempunyai berbagai kelebihan, silika juga mempunyai kelemahan karena gugus silanol $(-\mathrm{SiOH})$ dan siloksan (Si-O-Si) yang terkandung dalam 
membran silika mempunyai sifat keasaman yang rendah dan mempunyai oksigen sebagai atom donor yang sifatnya lemah. Hal ini dapat menyebabkan proses penyerapannya kurang optimal sebagai adsorben (Kristianingrum, dkk, 2011). Oleh karena itu perlu dilakukan modifikasi untuk meningkatkan daya serap adsorben.

Membran termodifikasi dibuat dengan cara menambahkan bahan pendukung supaya membran yang diperoleh mempunyai karakteristik yang baik. Salah satu bahan tersebut adalah kitosan. Kitosan merupakan biopolimer yang dapat digunakan sebagai bahan pembuatan membran. Kitosan adalah polisakarida kationik yang terdiri dari residu glukosamin dan Nasetilglukosamin yang terikat oleh ikatan $\beta-1,4$ glikosidik. Kitosan mengandung gugus amina bebas yang memberikan karateristik yang baik sebagai penukar ion (Shintia, 2013).

Berdasarkan uraian di atas, maka penelitian ini fokus pada sintesis membran silika-kitosan. Silika dapat diisolasi dengan metode leaching. Leaching adalah persitiwa pelarutan terarah dari satu atau lebih senyawa campuran padatan dengan cara mengontakkan dengan pelarut cair yang bersifat asam, dimana metode ini memiliki keuntungan seperti bersifat selektif terhadap sampel yang akan diisolasi (Karyasa, 2014). Silika yang diperoleh akan dijadikan membran, dimana membran silika dapat disintesis dengan menambahkan serbuk silika dengan agen perekat menjadi membran padat silikat. Kemudian membran yang dihasilkan akan diaplikasikan sebagai adsorben logam timbal $(\mathrm{Pb})$. Logam timbal $(\mathrm{Pb})$ adalah logam berat yang dapat mencemari udara, tanah dan air, sehingga apabila masuk ke dalam tubuh manusia akan mengganggu sistem saraf, merusak jaringan dan mempengaruhi kinerja ginjal (Darmono, 1995).

\section{METODE PENELITIAN}

\section{Alat}

Alat-alat yang digunakan dalam penelitian ini antara lain Atomic Absorption Spectroscopy (AAS), X-Ray Flourescence (XRF), rangkaian alat kromatografi kolom cair vakum (KKCV), neraca analitik, furnance, hotplate stirrer, magnetic strirrer, alat-alat gelas, cawan porselin dan wadah plastik berbahan PET (Polyethylene Terephthalate).

\section{Bahan}

Bahan-bahan yang digunakan dalam penelitian ini antara lain ampas tebu yang diambil dari daerah Takalar, Kabupaten Gowa Sulawesi Selatan, aquades $\left(\mathrm{H}_{2} \mathrm{O}\right)$, asam asetat $\left(\mathrm{CH}_{3} \mathrm{COOH}\right)$, asam klorida $(\mathrm{HCl})$, kertas saring whatman no.42, kitosan serbuk, natrium hidroksida $(\mathrm{NaOH})$, timbal nitrat $\mathrm{Pb}\left(\mathrm{NO}_{3}\right)_{2}$.

\section{Prosedur Kerja}

\section{Isolasi Silika dari Ampas Tebu}

Ampas tebu dibersihkan, dicuci dan dijemur di bawah sinar matahari langsung. Setelah kering ampas tebu diarangkan lalu digerus dengan menggunakan lumpang dan mortar, kemudian diabukan dengan menggunakan furnace pada suhu $800^{\circ} \mathrm{C}$ selama 4 jam. Abu diayak dengan 
menggunakan ayakan 100 mesh, kemudian dicuci dengan menggunakan larutan $\mathrm{HCl} 2 \mathrm{~N}$, diaduk selama 60 menit menggunakan magnetic stirrer. Selanjutnya disaring dengan menggunakan kertas saring whatman no.42 untuk mendapatkan endapan silika, kemudian dicuci dengan aquades hingga bersih dari larutan $\mathrm{HCl}$. Endapan silika yang telah diperoleh kemudian dikeringkan menggunakan oven pada suhu $105^{\circ} \mathrm{C}$. Selanjutnya, silika yang diperoleh dianalisis dengan menggunakan XRF (Erviana, 2013).

\section{Sintesis Membran Silika-Kitosan}

Pembuatan larutan natrium silikat $\left(\mathrm{Na}_{2} \mathrm{SiO}_{3}\right)$

Silika yang diperoleh dari abu ampas tebu ditimbang sebanyak $20 \mathrm{~g}$ kemudian ditambahkan larutan $\mathrm{NaOH} 4 \mathrm{M}$ sebanyak $158 \mathrm{~mL}$. Proses pelarutan tersebut dilakukan di atas hotplate stirrer pada suhu $80^{\circ} \mathrm{C}$ sampai mendidih dan mengental. Campuran silika dan $\mathrm{NaOH}$ yang diperoleh dituang ke dalam cawan porselen dan dilakukan peleburan dalam furnace pada suhu $500^{\circ} \mathrm{C}$ selama 30 menit. Padatan natrium silikat yang diperoleh dilarutkan dalam $200 \mathrm{~mL}$ aquades dan dibiarkan semalam, setelah itu disaring dan filtrat yang dihasilkan merupakan larutan natrium silikat (Bokau, 2013).

Pembuatan larutan kitosan

Kitosan ditimbang sebanyak $2 \mathrm{~g}$ kemudian dilarutkan dalam $100 \mathrm{~mL}$ asam asetat $2 \%$ dan diaduk dengan menggunakan magnetic stirrer hingga larut kemudian disonikasi dengan menggunakan ultrasonik selama 30 menit (Yunianti dan Dina, 2012). Larutan kitosan dan larutan silika (natrium silikat) yang telah dibuat dimasukkan ke dalam wadah plastik yang berbahan PET dengan perbandingan berturut-turut $1: 1 ; 1: 1,5 ; 1: 2 ; 1: 2,5$ dan $1: 3$, kemudian masingmasing campuran dihomogenkan, setelah itu didiamkan pada suhu kamar hingga membentuk membran padat. Membran kitosan silika yang diperoleh direndam dengan menggunakan $\mathrm{NaOH}$ 5\% selama 24 jam dan dicuci dengan menggunakan aquades hingga netral (Bokau, 2013).

Pembuatan larutan timbal $(\mathrm{Pb}) 100 \mathrm{ppm}$

Larutan baku $\mathrm{Pb} 1000$ ppm dipipet sebanyak $10 \mathrm{~mL}$ kemudian dimasukkan ke dalam labu takar $100 \mathrm{~mL}$. Setelah itu, dihimpitkan dengan aquades sampai tanda batas, lalu dihomogenkan.

Pembuatan larutan deret standar $\mathrm{Pb}$

Pembuatan larutan standar $\mathrm{Pb}$ dengan konsentrasi 10, 20, 30, 40 dan 50 ppm dilakukan dengan cara memipet larutan induk $\mathrm{Pb} 100 \mathrm{ppm}$ berturut-turut sebanyak 5, 10, 15, 20 dan 25 $\mathrm{mL}$ kemudian dimasukkan ke dalam labu takar $50 \mathrm{~mL}$. Setalah itu, dihimpitkan dengan aquades sampai tanda batas, lalu dihomogenkan.

\section{Adsorpsi Ion Logam Pb dengan Membran Silika-Kitosan}

Membran kitosan-silika diletakkan di atas corong yang telah dilapisi dengan kertas saring, kemudian larutan $\mathrm{Pb}\left(\mathrm{NO}_{3}\right)_{2} 50$ ppm sebanyak $50 \mathrm{~mL}$ dilewatkan pada membran. Larutan yang 
telah melewati membran, kemudian dianalisis dengan menggunakan AAS. Selanjutnya konsentrasi $\mathrm{Pb}$ teradsorpsi dapat dihitung dengan menggunakan rumus :

$$
\mathrm{Pb}_{\text {(teradsorpsi) }}=\mathrm{Pb}_{\text {(mula-mula) }}-\mathrm{Pb}_{\text {(sisa) }}
$$

\section{Penggunaan Membran Kitosan-Silika secara Readsorpsi}

Membran kitosan-silika yang telah digunakan dicuci dengan menggunakan larutan $\mathrm{NaOH}$ $5 \%$, kemudian diletakkan di atas corong yang telah dilapisi dengan kertas saring, selanjutnya larutan $\mathrm{Pb}\left(\mathrm{NO}_{3}\right)_{2} 50 \mathrm{ppm}$ dimasukkan ke dalam corong. Larutan yang telah melewati membran dianalisis dengan menggunakan AAS (Bokau, 2013). Selanjutnya konsentrasi Pb readsorpsi dapat disintesis dengan menggunakan rumus :

\section{HASIL DAN PEMBAHASAN}

$$
\mathrm{Pb}_{\text {(teradsorpsi) }}=\mathrm{Pb}_{\text {(mula-mula) }}-\mathrm{Pb}_{\text {(sisa) }}
$$

\section{Kandungan Silika Ampas Tebu}

Hasil analisis menggunakan XRF menunjukkan bahwa kandungan silika yang terdapat pada ampas tebu cukup besar yaitu 73,40 \% (Tabel 3.1). Menurut Hanafi dan Nandang (2010) hasil uji kadar abu rata-rata dalam ampas tebu adalah 2,09\% dan hasil analisis kadar silika menggunakan AAS sebanyak 64,65 \%, sedangkan pada penelitian Kristianingrum (2011) kadar silika sekitar $55,5 \%$ - $70 \%$, dimana banyaknya kandungan silika pada ampas tebu tersebut dapat dimanfaatkan sebagai sumber untuk menghasilkan silika.

Tabel 1 Hasil analisis komposisi abu ampas tebu dengan menggunakan XRF

\begin{tabular}{cc}
\hline Komposisi & Konsentrasi $(\% \mathbf{b} / \mathbf{b})$ \\
\hline $\mathrm{SiO}_{2}$ & 73,40 \\
$\mathrm{Fe}_{2} \mathrm{O}_{3}$ & 18,43 \\
$\mathrm{~K}_{2} \mathrm{O}$ & 4,42 \\
$\mathrm{P}_{2} \mathrm{O}_{5}$ & 0,368 \\
$\mathrm{MnO}$ & 1,24 \\
$\mathrm{TiO}_{2}$ & 1,06 \\
$\mathrm{CaO}$ & 0,50 \\
$\mathrm{ZnO}$ & 0,0416 \\
$\mathrm{Nb}_{2} \mathrm{O}_{5}$ & 0,0113 \\
$\mathrm{MoO}_{3}$ & 0,0073 \\
$\mathrm{SrO}$ & 0,0719 \\
\hline
\end{tabular}

\section{Membran Silika-Kitosan}

Pada sintesis membran silika-kitosan metode yang digunakan adalah inversi fasa dimana metode ini sering digunakan dalam pembuatan membran. Metode inversi fasa merupakan proses dimana sebuah polimer diubah dari fasa cair ke fasa padat. 
Membran silika-kitosan yang dihasilkan pada penelitian ini yaitu berasal dari pencampuran larutan kitosan dan natrium silikat. Natrium silikat ditambahkan untuk sebagai perkursor sumber silika, dimana penambahan larutan ini bertujuan untuk membentuk porogen pada membran serta meningkatkan kinerja membran. Perbandingan kitosan dan silika yang digunakan pada penelitian ini yaitu $1: 1 ; 1: 1,5 ; 1: 2 ; 1: 2,5 ;$ dan $1: 3$ (v/v). Proses pencampuran larutan kitosan dengan larutan natrium silika dimulai dengan cara memasukan kitosan terlebih dahulu. Volume campuran larutan kitosan dan larutan natrium silikat disamakan agar diperoleh membran dengan ketebalan yang sama. Campuran ini diaduk dengan menggunakan magnetic stirrer yang bertujuan agar pencampuran dari kedua larutan tersebut tidak mengakibatkan gumpalan pada membran. Jika terjadi penggumpalan pada membran maka mengakibatkan tertutupnya pori-pori pada membran yang dapat mempengaruhi daya adsorpsi membran.

Membran yang telah dimagnetic stirrer kemudian disonikasi dengan menggunakan ultrasonik. Sonikasi ini bertujuan untuk menghomogenkan campuran kitosan dan silika yang telah dicampurkan. Menurut Handayani, dkk.(2009), sonikasi akan menghasilkan membran dengan homogenitas yang lebih baik. Campuran silika-kitosan yang telah homogen kemudian dicetak menggunakan cetakan berbahan PET. Pada proses pencetakan membran silika-kitosan sangat dianjurkan untuk menghindari penggunaan bahan gelas maupun kaca sebagai media cetak, hal ini dilakukan untuk menghindari adanya interaksi antara silika dengan media cetakan.

Membran yang telah dicetak kemudian didiamkan dengan tujuan pelarut menguap secara perlahan sehingga terjadi pengentalan pada membran. Selanjutnya membran silika-kitosan direndam dengan natrium hidroksida $(\mathrm{NaOH}) 5 \%$. Perendaman dengan menggunakan $\mathrm{NaOH}$ bertujuan untuk mengkoagulasikan membran silika-kitosan agar diperoleh membran yang lebih stabil.

\section{Logam Timbal (Pb) yang Diadsorpsi oleh Membran Silika-Kitosan}

Kadar logam timbal yang teradsorpsi oleh membran silika-kitosan dengan konsentrasi awal $50 \mathrm{ppm}$, dapat dilihat pada Tabel 2.

Membran silika-kitosan dapat digunakan sebagai adsorben untuk menurunkan kadar logam berat dalam larutan atau limbah cair melalui proses adsorpsi. Adsorpsi merupakan metode yang efektif untuk mengatasi masalah pencemaran lingkungan. Metode adsorpsi bergantung pada kemampuan permukaan adsorben untuk menarik molekul-molekul gas, uap atau cairan. Proses adsorpsi dapat dilakukan dengan cara filtrasi, yaitu dengan melewatkan larutan timbal dengan membran silika-kitosan yang telah dibuat.

Pada Tabel 2 ditunjukkan hasil analisis ion logam $\mathrm{Pb}$ pada membran dan daya adsorpsi membran silika-kitosan dari berbagai perbandingan. Berdasarkan data tersebut diketahui bahwa membran silika-kitosan 1:2 merupakan membran yang mempunyai efektifitas tertinggi yang dapat mengadsorpsi logam timbal sebanyak 27,44 ppm. Hal serupa yang dihasilkan oleh Setyaningrum dkk (2014) dimana membran silika-kitosan abu sekam padi yang diperoleh dapat 
mengadsorpsi logam kadmium dan tembaga secara optimal pada membran dengan perbandingan $1: 2$.

Tabel 2 Hasil analisis logam timbal dengan menggunakan AAS setelah proses adsorpsi

\begin{tabular}{|c|c|c|c|c|c|}
\hline No & $\begin{array}{l}\text { Kitosan : silika } \\
\text { (volume } 50 \mathrm{~mL} \text { ) }\end{array}$ & $\begin{array}{l}\text { Absorbansi } \\
\text { dari Pb sisa }\end{array}$ & $\begin{array}{r}\text { Pb sisa } \\
\text { (ppm) }\end{array}$ & $\begin{array}{c}\text { Pb } \\
\text { teradsorpsi } \\
(\mathbf{p p m})\end{array}$ & $\begin{array}{c}\text { Kemam } \\
\text { puan } \\
\text { readsorpsi }\end{array}$ \\
\hline 1 & $\begin{array}{c}1: 1 \\
(25: 25)\end{array}$ & 0,1475 & 29,5 & 20,5 & $41 \%$ \\
\hline 2 & $\begin{array}{c}1: 1,5 \\
(20: 30)\end{array}$ & 0,1406 & 28,12 & 21,88 & $43,76 \%$ \\
\hline 3 & $\begin{aligned} 1 & : 2 \\
(16,7 & : 33,3)\end{aligned}$ & 0,1128 & 22,56 & 27,44 & $54,88 \%$ \\
\hline 4 & $\begin{array}{c}1: 2,5 \\
(14,3: 35,7)\end{array}$ & 0,1541 & 30,82 & 19,18 & $38,36 \%$ \\
\hline 5 & $\begin{aligned} 1 & : 3 \\
(12,5 & : 37,5)\end{aligned}$ & 0,1510 & 30,2 & 19,8 & $39,6 \%$ \\
\hline
\end{tabular}

Membran yang dihasilkan dengan perbandingan $1: 1$ dapat mengadsorbsi logam timbal sebesar 20,5 ppm dan pada perbandingan $1:$ 1,5 dapat mengadsorpsi logam timbal sebesar 21,88 ppm. Sedangkan pada perbandingan $1: 2,5$ dan $1: 3$ mengalami penurunan daya serap. Adanya penurunan daya adsorpsi tersebut dapat dikaitkan dengan berkurangnya kitosan pada membran atau berkurangnya gugus $\mathrm{NH}_{2}$ yang terdapat dalam membran.

Membran silika-kitosan dipengaruhi oleh situs aktif yang ada di dalam membran silikakitosan, yaitu gugus $\mathrm{NH}_{2}$ dan $\mathrm{O}^{2-}$ silika yang terikat pada monomer kitosan. Kitosan mengandung gugus amina bebas yang memberikan karateristik sebagai penukar ion dan mempunyai kemampuan untuk mengikat logam. Kemampuan kitosan untuk mengikat logam dengan cara pengkhelat adalah dihubungkan dengan kadar nitrogen yang tinggi pada rantai polimernya. Sedangkan pada silika untuk mengikat logam yaitu pada gugus $\mathrm{O}^{2-}$ dimana pada gugus tersebut bermuatan negatif dan akan mengikat ion logam karena pada logam tersebut bermuatan postif.

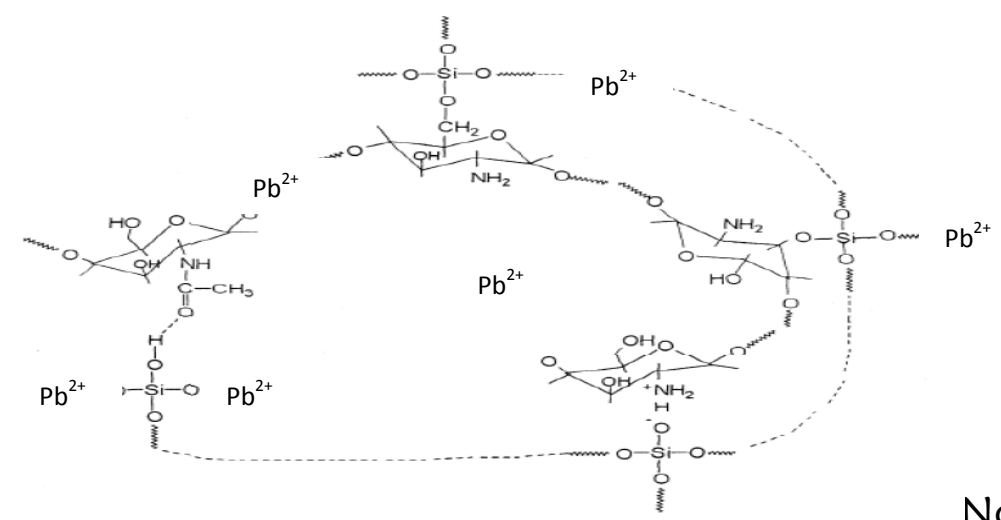


$\mathrm{Pb}^{2+}$

Gambar 1. Reaksi Membran Silika-Kitosan dengan Ion Logam Timbal

Membran yang telah digunakan dapat digunakan kembali untuk mengadsorpsi (readsorpsi) logam-logam. Pada penelitian ini, membran yang digunakan adalah membran yang daya adsorpsinya tinggi yaitu membran dengan perbandingan 1 : 2. Membran digunakan kembali untuk mengadsorpsi logam timbal, dimana larutan logam timbal dengan konsentrasi yang sama dilewatkan kembali melalui membran dengan proses filtrasi. Setelah itu, larutan yang melewati membran dianalisis kembali dengan AAS. Hasil tersebut menunjukkan membran silika-kitosan dengan perbandingan 1:2 mengadsorpsi kembali logam timbal yaitu sebesar 20,1 ppm dengan kemampuan readsorpsi membran sebesar 40,2\%. Hal ini membuktikan bahwa membran silikakitosan dapat digunakan kembali dalam proses adsorpsi untuk menurunkan kadar larutan ion logam timbal.

\section{PENUTUP}

\section{Kesimpulan}

Berdasarkan dari hasil penelitian yang telah dilakukan, dapat disimpulkan bahwa:

1. Kandungan silika dalam bentuk senyawa oksidanya yang terdapat pada abu ampas tebu setelah proses furnace dan proses leaching yang telah dianalisis dengan menggunakan $x$-ray fluorescence (XRF) yaitu sebesar 73,40\%.

2. Kemampuan adsorpsi logam timbal pada membran kitosan-silika dengan perbandingan 1 $: 1 ; 1: 1,5 ; 1: 2 ; 1: 2,5$ dan $1: 3$ yaitu berturut-turut sebesar $41 \%, 43,76 \%, 54,88 \%, 38,36 \%$ dan $39,6 \%$.

3. Readsorpsi membran kitosan-silika 1 : 2 yaitu sebesar 20,1 ppm dengan kemampuan readsorpsi sebesar 40,2\%.

\section{DAFTAR PUSTAKA}

Bokau, Nova Shintia. 2013. Sintesis Membran Kitosan Termodifikasi Silika Abu Sekam Padi Untuk Proses Dekolorisasi, Skirpsi Jurusan Kimia Fakultas Matematika dan Ilmu Pengetahuan Alam Universitas Negeri Semarang.

Darmono. 1995. Logam Dalam Sintem Biologi Makhluk Hidup”. Jakarta: Universitas Indonesia (UI-Press).

Erviana, Luana. 2013. Isolasi Silika Dari Tongkol Jagung, Skripsi Program Studi Teknik Kimia Fakultas Teknologi Industri Universitas Pembangunan Nasional "Veteran” Jawa Timur. 
Hanafi dan Nandang. 2010. Studi Pengaruh Bentuk Silika dari Abu Ampas Tebu Terhadap Kekuatan Produk Keramik. Jurnal Kimia Indonesia 5(1):1-8

Handayani, dkk.2014. Pemanfaatan Limbah Sekam Padi Menjadi Silika Gel. Jurnal Bahan Alam Terbarukan 3(2): 55-59

Karyasa, I Wayan. 2014. Pembuatan Ultra Fine Amorphous Silica (UFAS) Dari Jerami dan Sekam Padi”. Jurnal Sains dan Teknologi, 3(1): 264-274.

Kristianingrum, dkk.2011. Pengaruh Jenis Asam Pada Sintesis Silika Gel Dari Abu Bagasse Dan Uji Adsorptifnya Terhadap Ion Logam Tembaga (II). Prosiding Seminar Nasional Kimia. FMIPA. Yogyakarta. Universitas Negeri Yogyakarta

Naraputro dan Purwono. 2009. Pengelolahan Tanaman Tebu (Saccharum officinarum L.) Di Pabrik Gula Krebet Baru, PT. PG. Rajawali I, Malang Jawa Timur; Dengan Aspek Khusus Mempelajari Produktivitas Pada Tiap Katagori Tanaman. Makalah Seminar Depertemen Agronomi dan Hortikultular. Institut Pertanian Bogor.

Shintia, dkk. 2014. Sintesis Membran Kitosan Termodifikasi Silika Abu Sekam Padi Untuk Proses Dekolarisasi. Skripsi. Universitas Negeri Semarang.

Setyaningrum, Dyah dkk., 2014. Sintesis Membran Kitosan-Silika Abu Sekam Padi Untuk Filtrasi Ion $\mathrm{Cd}^{2+}$ dan $\mathrm{Cu}^{2+}$, Skripsi. Universitas Negeri Semarang

Yunianti dan Dina, 2012. Pemanfaatan Membran Kitosan-Silika Untuk Menurunkan Kadar Ion Logam Pb (II) Dalam Larutan. UNESA Journal Of Chemistry 1(1): 108-115 